\title{
Cyberculture: Change and Rehabilitation the Body
}

\author{
Sergiy Putrov \\ Doctor of Philosophical Sciences, Assistant Professor, \\ National Pedagogical Dragomanov University \\ (Kyiv, Ukraine) \\ E-mail: sergiy_putrov@ukr.net \\ ORCID: 0000-0002-2789-1355
}

\section{Galina Ivanova}

\author{
M.D., Senior Lecturer, National Pedagogical Dragomanov University \\ (Kyiv, Ukraine) \\ E-mail: ivanova_galina_npu@ukr.net \\ ORCID: 0000-0003-4202-4804
}

\begin{abstract}
In the article, the authors considered the ideas related to change and rehabilitation the body within the boundaries of a new social phenomenon, syberculture. As a result of the research, the authors concluded that the expansion of the possibilities of self, due to body composition changes and creation of the cybernetic organism is one of the possible scenarios for the development of future human being. Changes which happen in the Universe, which are considered and predicted in the paradigm of the Mental Universe, approve in the science new understanding of the place of man and the sense of his life. Change and rehabilitation the body are considered by the authors as the integral quality of everyday life of man of the future, which provides expansion of the opportunities of self. Such approach changes the attitude towards disabled people who are forced to use the modern technologies in body composition changes, and who assert self priority over a body on the example of one's personal life. The authors believe that man of the future will have to turn to the experience of affirming self over a body of a disabled person and use it to adapt one's body to the conditions of the changing Universe.

Keywords: cyberculture, transhumanism, Transhumanist Declaration, body composition changes, disabled people, the cyborg theory, cybernetic organism, Mental Universe
\end{abstract}

Received: February 25, 2018; accepted: May 9, 2018

Philosophy and Cosmology, Volume 21, 2018: 116-122

DOI: $10.29202 /$ phil-cosm/21/12

\footnotetext{
(C) Putrov, Sergiy, 2018

(C) Ivanova, Galina, 2018
} 


\section{Introduction}

Let's specify the terminology and make a brief analysis of the works devoted to cyberculture. Cyberculture or internet culture is considered by us as the intensively developing culture of communication, entertainment and business with the use of computer networks. Cyberculture is a new, adopting sustainable characteristics, social phenomenon, based on new understanding of the equipment and technologies in human life. As a social phenomenon, cyberculture provides: identification, security, confidentiality, rehabilitation, the formation and development of social relations in a virtual environment, such as online communities, online multi-player gaming, wearable computing, social gaming, social media, mobile apps, augmented reality, and texting. In "The Language of New Media" Lev Manovich offers the first systematic and rigorous theory of new media. He shows how new media works create the illusion of reality, address the viewer, and represent space. He also analyzes categories and forms unique to new media, such as interface and database [Manovich, 2001]. Social manifestations of cyberculture are considered in numerous works, for example, Olga Brunnerová and Jakub Charvát [Brunnerová \& Charvát, 2017]; David Bell, Brian D. Loader, Nicholas Pleace, and Douglas Schuler [Bell et al., 2004]; etc.

The analysis of researches in this area shows that the term cyberculture is used quite widely: from the cultures of virtual communities to cybernetics, cyborgization of the human body and human society itself. According to David J. Bell et al. cyberculture includes: artificial intelligence, cyberfeminism, cyberpunk, electronic government, games, HTML, Java, netiquette, piracy [Bell et al., 2004].

The history of cyberculture is stated in the article by Jakub Macek. Conclusions to which the author has come are relevant in our days. The conclusions made by the author are relevant in our days. Macek has formulated them as two hypotheses [Macek, 2005]:

1. Themes that I describe as the core of cybercultural narratives are common for all narratives originating from early cyberculture and they were reflected in expectations connected with the supposed characteristics of advanced information and communication technologies.

2. Values and expectations connected with cyberculture and advanced information and communication technologies were adopted by the majority society and became part and parcel of everyday political and economic ideology of "information technologies" and currently they play an important role in the hierarchization of the world of new technologies.

Thus, the authors consider cyberculture as "the world of new technologies" which is created by man, and in which man expands possibilities of self. In the article, authors allocated and considered only one of the directions "the world of new technologies", which is connected with the researches of change and rehabilitation the body.

\section{Transhumanism}

In hierarchy of the social relations, which are formed by cyberculture, the ideas of change and rehabilitation the body belong to transhumanism (abbreviated as $\mathrm{H}+$ or $\mathrm{h}+$ ), to one of the basic directions of cyberculture. Now transhumanism is an international intellectual movement that aims to transform the human condition by developing and making widely available sophisticated technologies to greatly enhance human intellect and physiology. There is an official site of the worldwide transhumanist movement, Humanity+ (https:// humanityplus.org/). It is noted on the website that Humanity+ is an international nonprofit 
membership organization that advocates the ethical use of technology, such as artificial intelligence, to expand human capacities. In other words, we want people to be better than well. This is the goal of transhumanism (https://humanityplus.org/).

The main ideas of transhumanism are stated in The Transhumanist Declaration, the first option of which was created in 1998. In subsequent years The Transhumanist Declaration was finalized and specified. Final version of The Transhumanist Declaration was adopted by the Humanity+ Board in March, 2009 [Bostrom, 2005; The Transhumanist Reader, 2013]. The Transhumanist Declarationncan be found on the website Humanity+ (https://humanityplus. org/philosophy/transhumanist-declaration/). The first and last items of The Transhumanist Declaration are important for our research:

1. Humanity stands to be profoundly affected by science and technology in the future. We envision the possibility of broadening human potential by overcoming aging, cognitive shortcomings, involuntary suffering, and our confinement to planet Earth.

2. We favour allowing individuals wide personal choice over how they enable their lives. This includes use of techniques that may be developed to assist memory, concentration, and mental energy; life extension therapies; reproductive choice technologies; cryonics procedures; and many other possible human modification and enhancement technologies.

Some important, from our point of view, ideas follow from The Transhumanist Declaration, which we will discuss in this article. These ideas are associated with change and rehabilitation the body. The first idea, for any person it is important to maintain the integrity of self and the inner peace. Modern technologies allow not only to change a structure of the body and compensate even its significant disadvantages, but also to consider the change and recovery the body as a necessary condition for the survival of man in the changing Universe. The second idea, change and rehabilitation the body is the direction of "the world of new technologies" which will enter everyday life of man of the future, approximately also as cars, the Internet, mobile devices, etc. have entered life of modern man. Let's consider these ideas in more detail.

\section{Remaking the Body}

In the book "Remaking the Body: Rehabilitation and Change", Wendy Seymour interviews men and women who have suffered profound bodily paralysis, and explores how they deal with their appearance, relationships, sexuality, incontinence and sport [Seymour, 1998]. As a result of the analysis, Seymour found that even serious disturbances in the functioning of the body did not eliminate the desire of self toward the fullest self-realization. Man is a harmonious development of one's above all, which itself is the fullness and integrity of the emerging inner world. Self is the basis of all "human" features. In essence, the harmony of the structure and functions of self determines the harmony of human manifestations, including those related to the body.

Examples from the history of culture prove that the body composition does not affect the person's mental capabilities and the harmony of his self. Perhaps, the most striking example is the story of life of Stephen Hawking, who was director of research at the Centre for Theoretical Cosmology at the University of Cambridge. The example of the life of the famous physicist demonstrates us the opportunities of modern technologies to compensate the disharmony of body composition and to provide complete realization of self. It is important that the development of self was self-sufficient and harmonized in order to avoid conflict between self and impossibility to realize these opportunities because of the pathologies of the body. For this reason, it is important that: 
1. The shortcomings of the body composition are not emphasized and not actualized by the social environment. For this, the authors propose to change the perception and rehabilitation the body, and consider Remaking the Body in the paradigm of the Mental Universe.

2. The possibilities of "the world of new technologies" correspond to the possibilities of self in self-realization.

Wendy Seymour's book, on the one hand, expands understanding of the lives of disabled people, reveals their suffering, care and empowerment. The book reveals the complexity of the body composition changes, both in the emotional and conceptual embodiment. However, on the other hand, the book reveals the richest possibilities of transhumanism, allowing disabled people to find the second life, the harmony of self and the fullness of self-realization in society. The book reveals valuable links between lived experiences and theories, including the cyborg theory [Seymour, 1998].

For Donna Haraway, the creator of the cyborg theory, a cybernetic organism is a creature of social reality, which is involved in the social, political, gender, cultural relations [The Transhumanist Reader, 2013]. However, in Wendy Seymour's study, we see that a cybernetic organism is the sociology of the body primarily, it is the involvement of self in "the world of new technologies." Cyberculture and transhumanity in particular, allow self to consider the technique and technologies as the most important composition of a body, which not only and not just compensates its shortcomings but expands possibilities of self in self-realization. The technique and technologies are involved in a body composition changes and become the main way of adaptation of self both to the changing environmental conditions, and to new scales of self-realization.

Seymour emphasizes the importance of the initial psychological orientation for disabled people. Essentially, the result of resolving the conflict between self and the body depends on it. To become over the body and consider "the world of new technologies" as a new qualitative step in realizing the possibilities of self, one must possess leadership qualities, holistic competence of leadership [Porvaznik et al., 2018]. The following factors depend on the formation of leadership qualities self: social adaptation, involvement in social relations, the fullness of self-realization and its other manifestations. According to the authors, regardless of the body composition, the outlook of the younger generations should be formed in accordance with the ideas of the Mental Universe. Involvement of self in the cosmic processes opens new prospects for use "the world of new technologies." The paradigm of the Mental Universe eliminates the conflict between self and a body, gives rise to new ideas for sociologists and health professionals concerned with rehabilitation.

\section{The role of education in change and rehabilitation the body}

An important role in the lives of disabled people and body composition changes is played by education. Education forms the basic characteristics of self: psychological stability, leadership qualities, the scale of the worldview, the direction of self-realization, perhaps, put in self by the nature. We want to draw attention to two key points that follow from the history of the formation and development of theories of education in the history of culture. The authors believe that these key points allow us to rethink the ideas of change and rehabilitation the body at a new qualitative level [Bazaluk \& Blazhevych, 2015; Bazaluk, 2018]:

Firstly, if we consider education as a way of life, i.e. in the traditions of ancient paideia, then the attitude to change and rehabilitation the body changes significantly. In this case, the body is considered as a means of achieving the goal. The main emphasis is shifted to 
the harmonization of self, to the formation of a specific ideal for imitation. Education, as a way of life, consists in creating a sustainable image of imitation, which a priori implies: the formation of the goal of life, an in-depth understanding of the meaning of life, drawing up a plan (scheduling on) for life and understanding the priorities. Education mobilizes the potential of self to achieve a specific ideal, an image for imitation. Education accents self to the profound self-understanding, self-discipline and self-education. It forms a certain direction of realization of self. In this case, the body composition fades into the background and is considered by self only as a means to achieve the ideal image. The body composition is considered as a technology, as the possibility of the fullest self-realization of self. Right here the idea of the cybernetic organism is born, which is regarded as the necessity of selfcomplication, as the only opportunity to achieve the fullness of realization of self, as an opportunity to achieve the goal. This approach to education changes attitudes toward the body initially. Change and rehabilitation the body is perceived by self as a technological innovation and progress, as one of the ways to use "the world of new technologies" for expansion of its own presence in the world around. Change and rehabilitation the body is used by self as a way of more qualitative achievement of the goal, the possibility to surpass the ideal, to become better and to go beyond the capabilities given at the birth. In essence, the use of the ideas of change and rehabilitation the body in everyday life is the first step towards man of the future.

The conflict between self and a body is eliminated. Olga Khrystenko, based on the achievements of modern embryology, sociology and bioethics, defined four levels of this conflict. The first level is a conflict concerning the life of the unborn child. The second one is a conflict concerning a mother. The third one is a conflict with the nation. The fourth one is a conflict with God [Khrystenko, 2016].

The authors consider that it is necessary to add one more level to these levels of the conflict: the conflict between self and a body. This conflict reaches apogee in the lives of disabled people. However, in the case when education is considered as a way of life, when disabled people are imposed a concrete ideal, an image for imitation, this conflict is eliminated, as accents in outlook are changed. Self and its harmonious development becomes the center, and a body is considered as an environment in which self develops. Change and rehabilitation the body are perceived as improvement or perfection of the environment in which self develops. It is the involvement of self in the paradigm of the Mental Universe, in which the body composition changes are the only possibility of opening up the Universe.

Secondly, if we regard education as a transcendence of humanity to the new levels of perfection, then change and recovery the body acquire completely new meanings, close to the cyborg theory. Education puts absolutely new perception of the equipment: as strengthening of the opportunities of self, as transtsendention out of limits of possible. Until now, education has been forming the relation of self to a body, as to the environment of the forced presence. The quality of formation and realization of self depends on the quality of the development of the body. The authors propose to change the key orientation and, instead of the body, "the world of new technologies" to consider as the place of the forced presence of self. In this case, self will treat technology as a body, and treat technique and technology as the sociology of the presence of self.

Such approach to technique and technology will change the attitude towards the transformation of the body, to its cybernification. Change and rehabilitation the body will turn into the daily necessity. For self, body composition changes and the transformation of the body into a cybernetic organism, will be the only opportunity to compete on the Earth 
and in space, and to adapt to the conditions of the expanding Universe as well. Just now, the physical and chemical characteristics of the Earth has changed intermittently, that leads to the death of people because of their inability to withstand natural disasters and technogenic catastrophes. Under the influence of the environmental conditions there is a transformation of biological and neurobiological processes in a human body. It is possible that the cybernetic organism will be the only potential solution to limit the destructive influence of the Universe on the development of self and its self-preservation [Slyuta, 2017].

\section{The paradigm of the Mental Universe}

The paradigm of the Mental Universe reveals the true possibilities of self and a body. According to Bernardo Kastrup, experiments have confirmed that — as predicted by quantum mechanics - reality is contextual, which contradicts at least intuitive formulations of realism and corroborates the hypothesis of a mental universe [Kastrup, 2017; Kastrup, 2018]. In the article "Making Sense of the Mental Universe" Kastrup explained how a mental universe can — at least in principle - accommodate (a) our experience of ourselves as distinct individual minds sharing a world beyond the control of our volition; and (b) the empirical fact that this world is contextual despite being seemingly shared [Kastrup, 2017].

For our study, the value of the paradigm of the Mental Universe is explained by the fact that man is regarded there as the evolution of self, and the change and rehabilitation the body - as a necessary condition for the involvement of self in the cosmic processes. The cyborg theory takes on the new meanings completely in the paradigm of the Mental Universe. Cybernization of the body becomes necessary and the only possible condition for human adaptation to the changing conditions of the Universe. This is the only possible way to expand the possibilities of self and its self-realization on the scale of the Universe [Matusevych \& Bazaluk, 2015].

The paradigm of the Mental Universe gives birth to new ideas for change and rehabilitation the body. For example, the development of the resources of the Universe implies a long-term presence of man in space. The biological organism, as the medium of the presence of self, is not adapted to a long-term staying in space [Space Travel, 2012]. Just for this reason, "the world of new technologies" becomes the only possibility of self to expand its presence in space, including the way of replacement of the biological systems of an organism by the artificial ones, i.e. the technique and technologies [Matusevych \& Bazaluk, 2015].

\section{Conclusion}

Thus, considering the ideas of change and rehabilitation the body, we came to new understanding of the place of man in the Universe, which follows from the paradigm of the Mental Universe. The authors consider that cyberculture and transhumanism, as one of the directions, predispose to change and rehabilitation the body. Adaptation to the changing conditions of the Universe, as well as opening up the cosmic resources, assumes the active involvement of self into the space processes. However, a human body, as a comlex functional biological system, is not ready for this. For this reason, for man of the future the following matters acquire a special urgency: 1) domination of self over the body; the initial attitude to the consideration of the possibilities of the body as a natural extension of the possibilities of self; 2) consideration of change and recovery the body as the only possible condition for the adaptation of self to the changing possibilities of one's own structure and functions, and also to the physical and chemical conditions of the expanding Universe. The authors established 
that in the change and rehabilitation the body the special importance is gained by education which is intended to form steady understanding of prevalence of self over a body. The future human being in "the world of new technologies", as the education philosophy problem, was considered in article "Cyborg, Mutant, Androgyne: The Future Human Being — What Will It Be Like? (Issues of Philosophy of Education)" by Tetiana Matusevych and Oleg Bazaluk [Matusevych \& Bazaluk, 2015]. However, from our point of view, only when the paradigm of the Mental Universe dominates, the conflict between self and the body is eliminated, because the body is viewed by self as a means to expand its opportunities. The body as a means of empowering self is a cybernetic organism.

\section{References}

Bazaluk, Oleg. The Feature Transformations of the Basic Meanings of Greek Paideia in the Educational Theories in the Middle Ages. $\Sigma X O \Lambda H$ (Schole), Vol. 12.1, 2018: 243 258. DOI: 10.21267/AQUILO.2018.12.10428.

Bazaluk, Oleg, and Tamara Blazhevych. Modern Basics of the Philosophy of Education. Future Human Image. 2 (5), 2015: 93-100.

Bell, David J., Brian D. Loader, Nicholas Pleace, and Douglas Schuler. Cyberculture: The Key Concepts. Routledge: London, 2004.

Bostrom, Nick. A History of Transhumanist Thought. In Journal of Evolution and Technology,

Vol. 14 (1), 2005: 1-25. http://www.nickbostrom.com/papers/history.pdf

Brunnerová, Olga and Jakub Charvát. Research Methods of Political Communication in New Media: A Review Study. Politické vedy, Volume 20, Number 3, 2017: 116-149.

Kastrup, Bernardo. Making Sense of the Mental Universe. Philosophy and Cosmology. Volume 19, 2017: 33-49.

Kastrup, Bernardo. The Next Paradigm. Future Human Image, Volume 9, 2018: 41-51.

Khrystenko, Olga. Education of a Future Human is the Key to Solving the Global Problems Facing Humanity. Future Human Image, 3 (6), 2016: 46-52.

Macek, Jakub.Defining Cyberculture.2005.http://macek.czechian.net/defining_cyberculture. htm

Manovich, Lev. The Language of New Media. Cambridge, Massachusetts: MIT Press, 2001.

Matusevych, Tetiana and Oleg Bazaluk. Cyborg, Mutant, Androgyne: The Future Human Being - What Will It Be Like? (Issues of Philosophy of Education). Dialogue and Universalism, Vol. XXV, № 2/2015: 175-181.

Porvaznik, Jan, Ivana Ljudvigova and Andrea Čajková. Holistic Competence of Leadership and Managerial Subjects. Politické vedy, Volume 21, Number 2, 2018: 56-77.

Seymour, Wendy. Remaking the Body: Rehabilitation and Change. Routledge, 1998.

Slyuta, Evgeniy. Problems of Research and Mining of Gas Deposits on the Moon. Mining of Mineral Deposits. 11 (4), 2017:117-125. https://doi.org/10.15407/mining11.04.117

Space Travel. Edited by Oleg Bazaluk. Kharkov: ISPC, FLP Kovalenko A.V., 2012. Book 2. $-240 \mathrm{p}$.

The Transhumanist Reader: Classical and Contemporary Essays on the Science, Technology, and Philosophy of the Human Future. Edited by Max More and Natasha Vita-More. Wiley-Blackwell, 2013. 